\title{
A Histomorphological Study of Nephrectomy Specimens in Rural Rajasthan- A Population Based Study
}

\author{
Sumit Gupta ${ }^{1}$, Kalpana Sankhala ${ }^{2}$, Madhvi Sanwalka ${ }^{3}$, Jyotsana Khatri' ${ }^{4}$, Deepak Kumar ${ }^{5}$ \\ ${ }^{1}$ Department of Pathology, NIMS, Medical College, Jaipur, Rajasthan, India. ${ }^{2}$ Department of \\ Pathology, NIMS, Medical College, Jaipur, Rajasthan, India. ${ }^{3}$ Department of Pathology, NIMS, \\ Medical College, Jaipur, Rajasthan, India. ${ }^{4}$ Department of Pathology, NIMS, Medical College, Jaipur, \\ Rajasthan, India. ${ }^{5}$ Department of Pathology, NIMS, Medical College, Jaipur, Rajasthan, India.
}

\section{ABSTRACT}

\section{BACKGROUND}

Nephrectomy brings in relief to patients from various chronic and life threatening diseases and in some cases makes way for renal transplant. Renal cell carcinoma accounts for $3 \%$ of all cancer deaths. Staging and grading remain the most useful indicators. Hence the present study was undertaken to become familiar with the morphological features and to explore, elucidate and document the kidney lesions at nephrectomy. We wanted to study the spectrum of renal lesions post nephrectomy, obtain the overall frequency, the age and sex incidence of various lesions at nephrectomy along with detailed histomorphology study of various lesions encountered in nephrectomy specimens and evaluate the histomorphological study of renal tumours including the classification of cell type, architectural pattern and grading.

\section{METHODS}

This prospective study was done on 85 nephrectomy specimens received in the department of pathology, N.I.M.S. Medical College, Jaipur, over a period of three years (2016 to 2019).

\section{RESULTS}

Of these 85 nephrectomy specimens, 44 cases (51.7\%) were neoplastic and remaining 41 cases ( $48.2 \%)$ were non-neoplastic.

\section{CONCLUSIONS}

The youngest patient was 40 days and oldest was 75 years. Chronic pyelonephritis was the commonest non-neoplastic lesion. Renal cell carcinoma was the commonest tumour and was commoner in males with clear cell variant being the most frequent. Monophasic Wilms tumour was the commonest neoplastic lesion in the paediatric population.

\section{KEY WORDS}

Nephrectomy, Chronic Pyelonephritis, Renal Cell Carcinoma
Corresponding Author:

Dr. Sumit Gupta,

Associate Professor

Department of Pathology

N.I.M.S. Medical College

Jaipur, Rajasthan, India.

E-mail:drsumitpatho@yahoo.com

DOI: $10.14260 / \mathrm{jemds} / 2020 / 475$

How to Cite This Article:

Gupta S, Sankhala K, Sanwalka M, et al. A histomorphological study of nephrectomy specimens in rural Rajasthan- a population based study. J. Evolution Med. Dent. Sci. 2020;9(31):2181-2186, $10.14260 /$ jemds $/ 2020 / 475$

Submission 26-04-2020,

Peer Review 21-06-2020,

Acceptance 29-06-2020,

Published 03-08-2020.

Copyright (c) 2020 JEMDS. This is an open access article distributed under Creative Commons Attribution License [Attribution 4.0 International (CC BY 4.0)] 


\section{BACKGROUND}

Human kidneys filter more than 1700 litres of blood per day to form more than one litre of urine. Kidney has diverse physiologic functions, complex anatomy, and gets affected by wide range of pathologic processes. Renal diseases are responsible for a great deal of morbidity, rather than mortality. In severe cases chronic renal disease ultimately destroys the renal parenchyma of both the kidneys, culminating in chronic renal failure. The most common lesions encountered in kidney today are certain inflammatory and neoplastic lesions. Nephrectomy brings in relief to patient from various chronic and life threatening diseases and in some cases make way for renal transplant. Renal cell carcinoma comprise of $3 \%$ of all cancer deaths. Staging and grading remain the most useful indicators for prognosis in renal neoplasia amidst the increasingly sophisticated techniques such as cytophotometry and molecular biological assessment. Hence the present study was undertaken to become familiar with the morphological features and to explore, elucidate and document the kidney lesions at nephrectomy.

The first nephrectomy was performed by Welle for removal of perirenal fibrolipoma.(1) Cadaveric nephrectomy for renal transplant came into practise in early $1960 \mathrm{~s}$ following introduction of effective immunosuppression therapy. (2)

Adult polycystic kidney disease is an important cause of renal failure and is responsible for $8 \%$ to $10 \%$ of all end stage kidney disease. (3) Autosomal recessive polycystic kidney is a rare genetic disorder. The gene is located on chromosome 6 , the liver and kidney are invariably affected.(4) In medullary cystic disease; corticomedullary junction has variable number of small cysts containing fluid resembling urine.(4) Acquired renal cystic disease are usually incidental findings noted at autopsy and rarely produce clinical symptoms unless they are very large.(5) Diabetic nephropathy does not develop in all diabetic patients. The cumulative incidence of nephropathy is $30 \%$ to $50 \%$ in IDDM and $10 \%$ to $15 \%$ in NIDDM.(6) Five major renal conditions are encountered in diabetic nephropathy includes vascular lesions, pyelonephritis, papillary necrosis, glycogen and fatty changes in tubular epithelium.(5) Chronic glomerulonephritis is best considered as the end stage of various types of glomerulonephritis. On cut section the cortex is thinned out and the perinephric fat is increased.(7)

In most cases of chronic pyelonephritis there is obvious obstruction of the urinary tract-obstructive chronic pyelonephritis.(7) Vesico- urethral reflex is present in the majority of children with non-obstructive chronic pyelonephritis. Non-obstructive chronic pyelonephritis affects females more often than males and may be found in any age.(8) Emphysematous pyelonephritis occurs mainly in female with uncontrolled diabetes mellitus( ${ }^{(9)}$ with papillary necrosis and thrombi are present in $20 \%$ of the cases. Xanthogranulomatous pyelonephritis was described in $1916,(10,11)$ with microscopy shows there is diffuse granulomatous inflammatory infiltrate that include large number of foamy histiocytes and multinucleate giant cells as well as lymphocytes, plasma cells and neutrophils. ${ }^{(1,12)}$ Malakoplakia has confluent nodules of homogenous yellowish tan tissue replacing large area of renal parenchyma.(13) Of patients infected with tuberculosis less than $0.5 \%$ will develop manifestations of renal disease. Majority of renal tuberculosis cases have bilateral renal involvement but frequently the extent of renal infection in one kidney far exceeded that of opposite. Urinary obstruction increases susceptibility to infection and to stone formation and unrelieved obstruction almost always leads to permanent renal atrophy, termed hydronephrosis. Nephrolithiasis common site are renal calyces, pelvis and bladder. If formed in renal pelvis they tend to remain small, average diameter of accretion of salts lead to development of branching staghorn calculi.(14,15) H.I.V. associated nephropathy consists of proteinuria, haematuria, azotaemia and renal failure. Few syndromes such as Meckel Gruber syndrome, Dandy-walker syndrome are associated with features of focal renal dysplasia.(16,17) In affected kidneys are usually enlarged, irregular and multicystic. The cysts are variable in size and number, some cyst containing clear fluid. It has totally lost its configuration and resemble cluster of grapes.(18) Nephrosclerosis refers to renal changes that occur with hypertension clinically. Grossly the kidneys are bilaterally affected and in late stages they are shrunken, cortical surface show peculiar flea - bitten appearance due to small pin point petechial haemorrhage.(19) In hyaline arteriosclerosis the outer part of the wall of the vessel is thickened by deposition of a homogenous, eosinophilic material and show atrophy of the smooth muscle cell in the vessel wall and uniform thickening of basement membrane.(19) Necrotizing arteriolitis (fibrinoid necrosis)of afferent arteriole is the hall mark of accelerated hypertension.

Renal cell carcinoma accounts for $85 \%$ of all primary renal tumours. (20) Next are the tumour of renal pelvis/ureter accounting for 7-8\%; the majority of them are transitional cell carcinoma. Nephroblastoma accounts for $5-6 \%$ of cases and various sarcoma of renal origin constitute remainder.(20,21) The presentation of RCC most commonly related to haematuria; flank pain or abdominal mass. The combination of these three diagnostic features, the so called classic triad, is found in approximately 10: of the patients. The cystic diseases cause a 50 -fold increase in the incidence of RCC and lead to the appearance of this tumour much earlier than in general populations. Grossly RCC occurs in the renal cortex as an irregular boss elated soft mass beneath the renal capsule. Cut surface shows solid golden yellow tumour sharply separated from the surrounding tissue by fibrous pseudocapsule. On microscopy, they exhibit one or mixture of four major histologic patterns- solid, glandular, papillary or spindled. The solid pattern is the most common while sarcomatoid or spindled is the least common variant.(22) Cystic change is not common in RCC. At least $15 \%$ of these tumours are found to be cystic on X ray or ultrasonography. Renal cell carcinoma is an unusual tumour in paediatric population.(22) Even though RCC spreads by direct invasion, lymphatic and blood stream, however blood borne metastasis is frequently a feature of renal cell carcinoma and spontaneous regression of metastasis has occasionally being described.(23,24) Papillary renal cell carcinoma has been recognized as a possible distinct sub -type of renal cell carcinoma and its histologic criteria for diagnostic and clinical outcome are still debated.(25) Papillary renal cell carcinoma often undergoes extensive necrosis and cyst formation and may exhibit prominent stromal infiltration by foamy macrophages.(26) Chromophobe renal cell carcinoma constitute less than $5 \%$ of all renal cell carcinoma with better prognosis. Typical variety has cells with tightly stained finely reticulated cytoplasm which stains positive with hales 
colloidal iron.(27.28) Collecting duct carcinoma is clinicopathologically a distinct variant of renal cell carcinoma which constitutes about $102 \%$ of all renal cell carcinomas, affect younger age -group than is typical for renal cell carcinoma and has poorer prognosis with most patients having metastasis at presentation with minimal nuclear Pleomorphism and mitosis. (29) It is recognized in world health organization classification that sarcomatoid change has been found to arise in all types of renal cell carcinoma, sarcomatoid features thus do not constitute a type per se but rather are an indication of progression in renal cell carcinoma.(30) Medullary carcinoma are highly aggressive tumours predominantly affecting young patients. Multilocular cystic renal cell carcinoma appears to be a distinct subtype of renal cell carcinoma with better prognosis and characteristic gross and microscopic features.(31) Juxtaglomerular cell tumour usually occurs in younger patients with female preponderance. The light microscopic picture is characterized by tumour cells with eosinophilic cytoplasm, arranged in trabeculae, sheet like, tubular or hemangiopericytoma-like patterns.(32)

Renal cell carcinoma grading is a prognostic parameter predictive of patient outcome. Four nuclear grades (1-4) were defined in the order of increasing nuclear size, irregularity and nucleolar prominence.

Oncocytoma is a distinct form of renal neoplasm with a favourable biologic behaviour. It accounts for about $7 \%$ of all renal parenchymal neoplasm. ${ }^{33,34)}$ Angiomyolipoma is a rare neoplasm composed of mixture of fat, blood vessel and vessel. They usually present as large, unilateral, symptomatic renal masses with intrarenal or retroperitoneal haemorrhage because of their vascular nature. Females are mostly affected.(35) Renal angiomyolipoma may sometimes cause fatal haemorrhage, sometimes there is involvement of regional lymph node. $(36,37,38)$ Non-Hodgkin's lymphoma involves the kidney more than Hodgkin's lymphoma. (39) Approximately 5$10 \%$ of primary renal tumours occur in renal pelvis and arise from pelvic urothelium comprising of transitional cell carcinoma, squamous cell carcinoma and adenocarcinomas. $(40,41,42)$

Nephroblastoma is the most common primary renal tumour of childhood and constitute $6 \%$ of all cancer in patients less than 15 years of age (120). Microscopically, three major components are seen comprising of blastemal, mesenchymal and epithelial tissue. Most tumours show all three components, but some can be monophasic or biphasic.(4) Multi cystic nephroma is an uncommon but distinctive lesion that arises in early infancy, but they may present clinically at any age. Clear cell sarcoma and Rhabdoid tumours are other paediatric tumours. ${ }^{(43,44)}$

\section{METHODS}

The present prospective study was done on the nephrectomy specimens sent for histopathological evaluation to the Department of Pathology. N.I.M.S. Medical College, Jaipur during a period of 3 years (July 2016 - July 2019). Following the receipt of nephrectomy specimen in $10 \%$ formalin, a detailed gross examination of the specimen was carried out. The required number of representative sections was taken for histopathological study. After routine paraffin processing, serial sections of 5 micron thickness were cut and routinely stained with haematoxylin and eosin stain. Detailed microscopic features were studied and recorded. The final diagnosis was arrived at after correlating the clinical features, gross and microscopic findings. Required relevant clinical and imaging details were obtained from patient case sheet or records whenever required. In the present study 85 nephrectomy specimens were analysed as per the proforma protocol. The study was approved by Institutional Ethics Committee and informed consent was obtained.

\section{Statistical Analysis}

The Statistical Package for Social Science \{SPSS Version 20 was used for Data Analysis. MS word and excel were used to generate graphs.

\section{RESULTS}

Out of 85 nephrectomy specimens received; 44 cases (51.7\%) were neoplastic and remaining 41 cases $(48.2 \%)$ were nonneoplastic. In the present study renal cell carcinoma was the commonest clinical/imaging diagnosis examined in 37 patients followed by hydronephrosis in 9 cases and pyelonephritis in 18 cases. 48 cases showed enlarged kidney while 18 were contracted kidney and remaining 15 were normal in size. The youngest patient in the study was aged 40 days old female and the oldest patient was 75 years old male. Maximum number of cases (22.4\%) were seen in the 6 th to 7 th decade. Chronic No significant difference was observed in the frequency of left or right side of kidney involved by nonneoplastic lesions. pyelonephritis was the commonest nonneoplastic lesion encountered in the age group of $31-40$ years. Hydronephrosis was commonest in the age group 21-30 years. Xanthogranulomatous pyelonephritis was also commonest between 21 -30 years.

The majority of the non-neoplastic kidney 34 (82.8\%) were normal; remaining 7 cases $(17.2 \%)$ were distorted. Majority showed dilatation and distortion of pelvicalyceal system with scarring ( 34 cases) followed by thinning of cortex (23 cases). Out of 44 neoplastic cases encountered were classified into parenchymal 34 (77.4\%); pelvic 5 (11.5\%) and primitive parenchymal (Wilms) in $5(11.3 \%)$ cases. The parenchymal tumours composed of renal cell carcinomas (33) and one case of angiomyolipoma. The pelvic tumours included 2 cases of transitional cell carcinoma: 2 cases of squamous cell carcinoma and I case of dedifferentiating sarcoma. There were 5 cases of Wilms tumour.

Renal cell carcinoma was the common nest tumour encountered in this study and was found to be frequent between 51 to 70 years of age. Wilms tumour was the next common seen in 5 cases. All neoplastic lesions was common in males. Male to female ratio in renal cell carcinoma was 2.6:1. Male to female ratio in Wilms was 4:1. Regarding the side and site of occurrence, there was no significant differences between right and left kidney and the upper and lower poles in case of renal cell carcinoma. The Wilms tumour involved entire cut surface in all cases.

The most common cellular architecture observed was solid seen in 19 (57.5\%) cases of renal cell carcinoma. The predominant cell type observed was clear cells in 29 cases, out 
of which 20 cases showed exclusively clear cells. The nuclear grade II was found to be most common (45.4\%). Out of 44 neoplastic cases; 4 cases were identified as renal pelvis tumours. The present study consisted of 3 monophasic, 1 biphasic and triphasic Wilms tumour.

\section{DISCUSSION}

Many non-neoplastic and neoplastic lesions constitute an indications for nephrectomy. The present study was an analysis of 85 nephrectomy specimens, which included 41 non-neoplastic (48.2\%) and 44 neoplastic lesions (51.7\%). The most common preoperative diagnosis on clinical examination/radiological imaging was renal cell carcinoma (42.3\%) followed by hydronephrosis (10.5\%). Non obstructive pyelonephritis is said to be less common than obstructive pyelonephritis. Non obstructive chronic pyelonephritis was found to be much more common as compared to obstructive chronic pyelonephritis, with only eight cases showing renal calculi. The reason for this could be that now days most cases of renal calculi are being treated conservatively and hence nephrectomy is not required in most of these cases. The most important cause of non-obstructive chronic pyelonephritis is vesicoureteric reflux. Pyelonephritis is seen in all age group with peak incidence in infancy and childhood, women of childbearing age and both men and women older than 60 years. (4) Specimen showed dilatation of the pelvicalyceal system. In cases of chronic pyelonephritis with hydronephrosis, the cortex was thinned out with loss of normal kidney tissue. The patchy distribution of the gross scar correlated with microscopic distribution of interstitial fibrosis. The peak study of hydronephrosis is below the age of 1 year and then again in elderly.(45) Various causes of obstruction leading to hydronephrosis include structural causes like calculi, tumours, foreign bodies, etc. and functional obstruction which includes neurogenic origin or due to reflux.(45) In present study, one case was associated with neurogenic bladder. All cases of hydronephrosis showed renal parenchyma thinning and atrophy in the present study. Staghorn calculi have been found in a large number of patients with xanthogranulomatous pyelonephritis, ${ }^{(45)}$ as was observed in $66.6 \%$ of xanthogranulomatous pyelonephritis in the present study. In multicystic renal dysplasia the left kidney was affected often than the right as mentioned in the literature.(46) In present study the left kidney was affected in $66.6 \%$ of cases of multicystic renal dysplasia.

It has been reported that the most frequent primary malignant tumours of the renal parenchyma are renal cell carcinomas and Wilms tumour.(12) The commonest primary malignant tumour of the renal pelvis have been found to be transitional cell carcinomas, but in the present study there were 2 cases each of transitional cell carcinomas and squamous cell carcinoma.

The incidence of renal cell carcinomas increases with advancing age(5) and thus majority of the patients in the present study were between 51 -70 years of age. Reports indicate a male: female ratio of about 3:1 for renal cell carcinoma.(5) In the present study, it was 2.6:1. The ratio tends to decrease with increasing age.(18) Ranshaw states that the clear cells or conventional renal cell carcinoma comprise $75 \%$ of all renal cell carcinomas. In the present study, $93 \%$ of the renal cell carcinoma was of the clear cell type.(43) Histological features of the renal cell carcinomas in our studies were similar to the findings observed in various literature. ${ }^{(43)}$ Nuclear grade of the tumour as determined in microscopic sections is an important predictor of survival. The most marked prognostic differences is between grades I and grade II on one side and grade III and IV on the other.(4) In the present study, 27 out of 33 renal carcinomas (81.8\%) showed nuclear grades I and II with 12 and 15 cases respectively. Six cases $(18.2 \%)$ showed nuclear grades III and IV.

Carcinoma of the renal pelvis is said to be rare, accounting for approximately $5 \%$ of the clinically evident primary malignant neoplasm of the kidneys ${ }^{(47.48)}$ and males have been found to be affected three to four times as commonly as women.(48) In the present study $75 / 5 \%$ were males and were in age of 60 to 80 years.

Most Wilms tumour have been found to be triphasic, with a representation of blastemal, mesenchymal and epithelial components. However, in the present study, majority of Wilms tumour had monophasic component (60\%) with only $20 \%$ showing triphasic components. Anaplasia has been reported in $7 \%$ of Wilms tumour and has been linked with poor prognosis. ${ }^{(43)}$ Anaplasia was found in $40 \%$ of Wilms tumour encountered in the present study.

\section{CONCLUSIONS}

Specimen of nephrectomy received was between $1^{\text {st }}$ to $8^{\text {th }}$ decades of life. The youngest was 40 days old and oldest was 75 years old. Neoplastic lesions which accounted for $51.7 \%$ of the cases, were more common than non-neoplastic lesions $(48.3 \%)$ as diagnosed by histopathology. Chronic pyelonephritis was the commonest non-neoplastic lesion in nephrectomy specimens. The peak age incidence of chronic pyelonephritis was between 21 to 40 years, in which $68.3 \%$ of chronic pyelonephritis occurred. Xanthogranulomatous pyelonephritis was more common in females and had a maximum incidence in 21 - 30 years age group. Renal cell carcinomas were the commonest tumours in the present study, accounting for $75 \%$ of renal neoplasm and $38.8 \%$ of the nephrectomies. Renal cell carcinoma was commoner in males. Clear cell variant was the most frequent. Most of the renal cell carcinomas $(81.7 \%)$ predominantly showed a low nuclear grade (I or II). Wilms tumour constituted $12.2 \%$ of total neoplastic lesions with maximum incidence around the age of 1 year and monophasic pattern was the commonest seen in $60 \%$ of Wilms tumours.

It can be concluded that for proper evaluation of nephrectomy specimens, a detailed clinical history and imaging findings are necessary. It needs coordination among clinician, radiologist and pathologist for accurate diagnosis and evaluation of the prognostic factors.

Financial or Other Competing Interests: None. 


\section{REFERENCES}

[1] Novick AC, Streamy SB. Surgery of the kidney. In: Walsh PC, Retik AB, Vaughan ED, et al, eds. Chambells urology. $6^{\text {th }}$ edn. Philadelphia: WB Saunders Co 1992:2413-500.

[2] Whitefield NH. Rob \& Smith's operative surgery: genitourinary surgery. $4^{\text {th }}$ edn. Oxford: ButterworthHeinemann Ltd 1993.

[3] Rubin E, Farber JL. The kidney. In: Pathology. 2nd edn. Philadelphia: J. B. Lippincott Co 1994:804-65.

[4] Order N. Urinary tract. In: Rosai J, Ackerman LV, eds. Rosai and Ackerman's surgical pathology. $9^{\text {th }}$ edn. St. Louis, Mo: Mosby 2004:1237-342.

[5] Alpers CE. The kidney, In: Kumar V, Abbar KA, Fausto N, eds. Robbins and Cortan pathologic basis of disease. $7^{\text {th }}$ edn. Philadelphia: WB Sounders Co 2014:995-1020.

[6] Knowles HC. Magnitude of renal failure problems in diabetic patients. Kidney Int 1974;(1):2-7.

[7] Liapis H, Gokden N, Hmiel P, et al. Histopathology, ultrastructure, and clinical phenotypes in thin glomerular basement membrane disease variants. Hum Pathol 2002;33(8):836-45.

[8] Smith JF. The diagnosis of the scars of chronic pyelonephritis. J Clin Pathol 1962;15(6):522-6.

[9] Hodson CJ, Wilson S. Natural history of chronic pyelonephritis scarring. Br Med Bj 1965;2(5455):191-4.

[10] McDonald GS. Xanthogranulomatous pyelonephritis. J Pathol 1981;133(3):203-13.

[11] Hammadeh MY, Ncholls G, Calder CJ, et al. Xanthogranulomatous pyelonephritis in childhood: Preoperative diagnosis is possible. Br J Urol 1994;73(1):836.

[12] Parsons MA, Harris SC, Longstaff AJ, et al. Xanthogranulomatous pyelonephritis: a pathological, clinical and aetiological analysis of 87 cases. Diagn Histopathol 1983;6(3-4):203-19.

[13] McClure J, Cameron CH, Garett R. The ultra-structural features of malakoplakia. J Pathol 1981;134(1):13-25.

[14] Gow JG, Barbosa S. Genitourinary tuberculosis. A study of 1117 cases over a period of 34 years. Br J Urol 1984;56(5):449-55.

[15] Holland NH, Kotchen T, Bhathena D. Hypertension in children with chronic pyelonephritis. Kidney Int 1975:S243-51.

[16] Hisa YE, Bratu M, Herbordt A. genetics of the meckel syndrome (Dysencephalia Splanchnocystica). Pediatrics 1971;48(8):237-47.

[17] Kudo M, Tamura K, Fuse Y. Cystic dysplastic kidneys associated with Dandy-Walker malformation and congenital hepatic fibrosis. Am J Clin Pathol 1985;84(4):459-63.

[18] Petersen RO. Urologic pathology. Philadelphia: J.B. Lippincott Company 1986.

[19] Rose GA. Renovascular hypertension: an update on pathophysiology. Br Med J 1957;2(11):1148-52.

[20] Bennington JL, Laubscher FA. Epidemiologic studies on carcinoma of the kidney. I. Association of renal adenocarcinoma with smoking. Cancer 1968;21(6):106971.
[21] Anisworth SK, Hirsch HZ, Brackett NC, et al. Diabetic Glomerulonephropathy: Histopathologic, Immunofluorescent, and Ultrastructural Studies of 16 Cases. Hum Pathol 1982;13(5):470-8.

[22] Medeiros LJ, Gelb AB, Weiss LM. Renal cell carcinoma. Prognostic significance of morphologic parameters in 121 cases. Cancer 1988;61(8):1639-51.

[23] Sidhu PS, Lewis M. Soft tissue metastasis from renal cell carcinoma. Br J Urol 1994;74(6):799-801.

[24] Adil G, Murat D. Renal cell carcinoma metastasis to parotid gland. Br J Urol 1989;63:600-4.

[25] Amin MB, Corless CL, Renshaw AA, et al. Papillary (Chromophil) renal cell carcinoma: histomorphologic characteristics and evaluation of conventional pathologic prognostic parameters in 62 cases. Am J Surg Pathol 1997;21(6):621-35.

[26] Van-Bernal JF, Mayorga M, García-Arranz P, et al. Mucin secretion in papillary (Chromophil) renal cell carcinoma. Am J Surg Pathol 1998;22(8):1037-9.

[27] Revter VE, Tickoo SK. Adult renal tumours. IN: Millis SE, ed. Sternbergs diagnostic surgical pathology. $9^{\text {th }}$ edn. St. Louis Mo: Mosby 2004:1237-342.

[28] Thoenes W, Storkel S, Rumpelt HJ, et al. Chromophobe cell renal carcinoma and its variant--a report on 32 cases. J Pathol 1988;155(4):277-87.

[29] Fleming S, Lewi HJ. Collecting duct carcinoma of the kidney. Histopathology 1986;10(11):1131-41.

[30] Eble JN, Sauter G, Epotein JI, et al. Classification of tumours of urinary system. Geneva: World Health Organization 2004.

[31] Murad T, Komaiko W, Oyasu R, et al. Multilocular cystic renal cell carcinoma. Am J Clin Patghol 1991;95(5):633-7.

[32] Tetu B, Vaillancourt L, Camilleri JP, et al. Juxtaglomerular cell tumour of the kidney: report of two cases with a papillary pattern. Hum Pathol 1993;24(11):1168-74.

[33] Fuhram SA, Lasky LC, Limas C. Prognostic significance of morphologic parameters in renal cell carcinomas. Am J Surg Pathol 1982;6(7):655-63.

[34] Warfel KA, Eble JN. Renal oncocytomatosis. J Urol 1982;127(6):1179-80.

[35] Wong AL, McGeorge A, Clark AH. Renal angiomyolipoma: a review of the literature and a report of 4 cases. Br J Urol 1981;53(5):406-11.

[36] Royce PL, Westmore DD, Brown RB. Rupture of renal angiomyolipoma. Aust NZ J Surg 1987;57(7):481-3.

[37] Tong YC, Chieng PV, Tasi TC, et al. Renal angiomyolipoma: report of 24 case. Brit J Urol 1990;66(6):585-9.

[38] Agarwal R, Agarwal PK, Dalela D. Renal angiomyolipoma with nodal involvement. A 20 year follow up. Brit J Urol 1995;76(4):517.

[39] Rao HSG, Saridhara K, Reddy R, et al. Burkitt's lymphoma of kidney and ovary: a case report and review of literature. India J Urol 1998;14(1):49-51.

[40] Johansson S, Angervall L, Bengtsson $U$, et al. A clinicopathologic and prognostic study of epithelial tumours of the renal pelvis. Cancer 1976;37(3):1376-83.

[41] Cadeddu JA, Jarrett TW. Hypercalcemia associated with squamous cell carcinomas of the renal pelvis. Am J Urol 1998;160(5):1798.

[42] Bhargava S. Tandom V. Papillary Mucoid adenocarcinoma of renal pelvis--report case with review literature. Indian J Cancer 1979;16(2):78-81. 
[43] Weeks DA, Beckwith JB, Mierau GW, et al. Rhabdoid tumour of kidney. A report of 111 cases from the national Wilms' tumour study pathology center. Am J Surg Pathol 1989;13(6):439-58.

[44] Suzer O, Baltaci S. Bilateral xanthogranulomatous pyelonephritis in a child. Br J Urol 1996;78(6):950-1.

[45] Porter KA. Tubulo-interstitial disease systemic pathology. In: St. Symmers CW, ed. The kidney. $3^{\text {rd }}$ edn. U.K: Churchill Livingstone 1997:431-89.
[46] Risdon RA. Renal dysplasia. I. A clinicopathological study of 76 cases. J Clin Pathol 2019;24(1):57-71.

[47] Rose GA. Renovascular hypertension: a clinicopathological study of 76 cases. J Clin Pathol 1971;24:57-65.

[48] Renshaw AA. Subclassification of renal cell neoplasm: an update for practising pathologist. Histopathology 2002:41(4):283-300. 